\title{
TUMOR MARKERS IN OVARIAN CANCER
}

\author{
Adina-Elena Nenciu' ${ }^{1}$, C. G. Nenciu ${ }^{2,3}$, R. Fodoroiu ${ }^{1}$, Olga Scalețchi ${ }^{1}$, Florica Șandru ${ }^{3,4}$, M. C. \\ Dumitrașcu ${ }^{1,3}$
}

\author{
${ }^{1}$ Bucharest University Emergency Hospital, Bucharest, Romania \\ 2"St. John” Emergency Hospital, Bucur Maternity Bucharest, Romania \\ 3"Carol Davila" University of Medicine and Pharmacy, Bucharest, Romania \\ 4“Elias" Emergency Hospital, Bucharest, Romania \\ Corresponding author: Nenciu Cătălin George \\ E-mail: dr.nenciu@yahoo.com \\ Phone no.: +40749023223
}

\begin{abstract}
Even if today's society is rapidly evolving there is still much that can be done. This applies in the oncological field. One of the main female health problems worldwide is represented by the gynecological cancers. Ovarian cancer is the main cause of mortality among women with gynecological cancers. Although its prevalence is lover compared to breast, uterine or cervical cancer, the mortality and morbidity rates are significantly higher. The first step in the management of ovarian cancer is represented by regular screening and rapid diagnosis. One of the most important tolls is represented by serological markers dosage in order to estimate the type of tumor before the gynecological specific intervention. There is a real need to identify correctly the ovarian cancer as early as possible in order to obtain the favorable prognosis that comes with the diagnosis in earlystage. Most of the ovarian cancers (above 90\%) are represented by carcinomas which are frequently diagnosed in advanced stages. The roles of the biomarkers are to indicate the malignancy of an ovarian tumor and to predict the relapse risk. The aim of this paper is to update the indications regarding the usage of serological markers in ovarian cancers and the importance of using them for our patients.
\end{abstract}

Keywords: tumor markers, ovarian cancer, diagnosis, prognosis

\section{Introduction}

It is considered that one of the most common cancers in female population is represented by ovarian cancer [1]. Unfortunately, this type of cancers has high mortality rate and the worst prognosis compared to cervical and uterine cancer [2]. Compared to breast cancer, ovarian cancers are considered to have a triple mortality rate although its prevalence is considerably lower [3]. The lifetime risk of ovarian malignant tumor is estimated to be around $2.7 \%$ if the female does not have protective factors and increases if the risk factors for cancer, decreased pregnancy, decreased lactation period and tube ligature are present $[4,5,6]$. Overall, the number of deaths related to ovarian cancer is above 180000 per year and represents $4.4 \%$ of all causes of death among women (in 2018, according to GLOBOCAN) [6] and high-grade serous carcinoma is responsible for most of them [7]. The predictors for high mortality are represented by comorbidities and the stage at the moment of diagnosis [8]. 
Malignant epithelial tumors represent the vast majority of ovarian cancers $(90 \%)$ with serous carcinoma, endometrial carcinoma, clear-cell carcinoma and mucinous carcinoma being the main types [9]. Malignant germ cell tumors and sex cord-stromal tumors are less common. Ovarian cancers have an important histopathology and immunohistochemistry variety [9]. In order to evaluate the tumor type or the evolution, the biochemical markers are used. They are considered to approach the ideal if the biomarker has an accurate in screening result (diagnosis in early stage) and an increased capacity of identifying the relapse [10].
Associated tumor markers in ovarian cancer that can be used are represented by cancer antigen 125 (CA 125), carcinoembryonic antigen, alphafetoprotein, carcinoembryonic antigen, cancer antigen 19-9 (Table 1). There can also be used inhibin, anti-Mullerian hormone, estradiol, testosterone, androstenedione, dehydroepiandrosterone, HCG and lactate dehydrogenase. In epithelial ovarian cancer, the first choice is represented by $\mathrm{CA} 125$, in choriocarcinoma ovary HCG is recommended, alpha-fetoprotein is the first choice for endometrial sinus tumor of ovary. In mixed germ cell tumor of ovary HCG and AFP can be used [11].

\begin{tabular}{|c|c|c|}
\hline $\begin{array}{l}\text { Ovarian cancer } \\
\text { WHO classification [12] }\end{array}$ & $\begin{array}{l}\text { Marker used } \\
\text { [11] }\end{array}$ & When it is recommended \\
\hline $\begin{array}{l}\text { Epithelial tumors } \\
\text { (serous, mucinous, } \\
\text { endometrioid, clear cell, } \\
\text { transitional cell tumors, } \\
\text { epithelial-stromal) }\end{array}$ & $\begin{array}{l}\text { CA125 (epithelial) } \\
\text { CEA (mucinous) }\end{array}$ & $\begin{array}{l}\text { Solid or cystic tumor (the most } \\
\text { frequently used marker) }\end{array}$ \\
\hline $\begin{array}{l}\text { Sex cord- stromal tumors } \\
\text { (granulosa, Sertoli) }\end{array}$ & $\begin{array}{l}\text { Estradiol } \\
\text { Testosterone } \\
\text { Anti-Mullerian hormone } \\
\text { Inhibin A and B }\end{array}$ & $\begin{array}{l}\text { The tumor can be suspicioned in } \\
\text { postmenopause or when abnormal } \\
\text { menstruations are present, } \\
\text { associated with modified secondary } \\
\text { sexual characteristics }\end{array}$ \\
\hline $\begin{array}{l}\text { Germ cell tumors } \\
\text { (teratoma, dysgerminomas) }\end{array}$ & $\begin{array}{l}\text { HCG } \\
\text { AFP } \\
\text { Lactate dehydrogenase } \\
\text { Placental alkaline } \\
\text { phosphatase (PALP) } \\
\end{array}$ & $\begin{array}{l}\text { They are most common in young } \\
\text { patients, before first period until } 30 \\
\text { years. The mostly have increased } \\
\text { dimensions and can be bilateral }\end{array}$ \\
\hline $\begin{array}{l}\text { Malignant, not otherwise } \\
\text { specified (metastatic cancer) }\end{array}$ & CA 19-9 & $\begin{array}{l}\text { When other cancer is suspicioned } \\
\text { or the patient has oncological } \\
\text { history }\end{array}$ \\
\hline
\end{tabular}

Table 1 - Markers used in different types of ovarian cancers

\section{CA 125}

CA125 is known as cancer antigen 125 , carbohydrate antigen 125 or tumor antigen 125 [13]. It has been used since 1981 when it has been described (the monoclonal antibody OC125 was isolated in ovarian tissue with cancer) [14] and in the past decades it was used to differentiate benign for malignant tumors and afterward to evaluate the evolution of the disease. CA 125 is a glycoprotein antigen (mucin-type glycoprotein) that is associated with the cellular membrane and has the molecular weight of 5 million Dalton. The MUC16 gene is responsible for synthetizing this glycoprotein [13]. The importance of CA 125 was studied in multiple points from before histopathological diagnosis for predicting the malignancy, until predicting the relapse and prognosis after it is used to evaluate the systemic therapy.

CA 125 has an essential role in differentiating early malignant ovarian tumors that appear in $10 \%$ of the tumors in premenopausal female and more than $40 \%$ in postmenopausal female [15]. One disadvantage is represented by low specificity and because of that its role alone in screening is limited. CA 125 can be elevated in multiple pathological and physiological cases as in normal menstruation or retrograde menstruation, pregnancy, endometriosis, adenomyosis or pelvic inflammatory disease. 
Due to this, CA 125 is more specific for ovarian cancer in postmenopausal women compared to premenopausal women.

CA 125 has its origin in coelomic epithelium and fetal amniotic epithelium. It is considered that it elevates in $47 \%$ of the cases in early stage and more than $90 \%$ in advanced stage [16]. In evaluating the evolution after treatment is considered that reducing by half is correlated with good response, whereas the progression and drug resistance is correlated with double values [17]. After surgical treatment and chemotherapy, the dosage of CA 125 is used to predict de recurrence when the marker is rising constantly. Although the correlation between increasing values and detection of recurrent disease in less than 5 months is established, some studies reported that the overall survival is not significant for the patients that received treatment at the beginning of CA 125 rising compared to the group of patients that begin treatment at relapse [18]. The use of serial monitoring of the marker and transvaginal ultrasound can increase the level of specificity [19].

\section{HE 4}

HE 4 (human epididymis protein 4) is a protein with molecular weight of $20-25 \mathrm{kDa}$ and is secreted by epithelial cells [17]. The gene responsible for synthetizing HE 4 (WFDC2 gene) was found to be increased in cancerous ovarian cancer compared to normal ovarian tissue and so serum HE4 protein level started to be used as marker [20]. Discovered by Kirchhoff in 1991, HE4 is a proteinase inhibitor with increased primary expression in some ovarian cancers [21]. The role of this protein is to sustain the adhesion of cancerous cells, not only in ovarian cancer but also in endometrial cancer for example [22]. HE4 sustains the cell proliferation in cancers whereas its inhibition is associated with the inhibition of the tumor growth [23].

HE4 immunoreactivity was highlighted in normal epithelium of different organs as breast, genital tract, renal tubules, respiratory system, colonic mucosa and salivary glands [22]. Positive immunoreactivity was encountered in different types of cancer but especially in ovarian cancer. There is a variation in HE4 expression in different types of cancer $(100 \%$ - endometrioid cancer, 50\%- clear-cell tumors, none in mucinous types) [22]. The interpretation of HE4 value must be done considering other pathologies that can contribute to increase this marker (like renal pathology or pulmonary cancer) [24, 25]. Compared to CA 125, HE4 is increased in postmenopause and decreased in pregnancy, but unchanged by menstrual cycle, contraceptive usage or endometriosis [22] (Table 2).

\begin{tabular}{llllll}
\hline Biomarker & $\begin{array}{l}\text { Benign } \\
\text { disease }\end{array}$ & Endometriosis & $\begin{array}{l}\text { Renal failure } \\
\text { Lung cancer }\end{array}$ & $\begin{array}{l}\text { Age } \\
\text { (Postmenopause) }\end{array}$ & Pregnancy \\
\hline CA 125 & $8 \%$ & $3 \%$ & Elevated & Decreased & Elevated \\
\hline HE 4 & $29 \%$ & $67 \%$ & - & Elevated & Decreased \\
\hline
\end{tabular}

Table 2 - Variation of CA125 and HE4

\section{ROMA score}

In order to distinguish between malignant and benign tumors, studies have evaluated the combined usage of CA125 and HE4. ROMA score (risk of malignancy algorithm) is approved and used worldwide for this purpose. The sensitivity is $92.3 \%$ in the premenopausal patients and $76.5 \%$ in postmenopausal patients and the specificity is $75 \%$ in premenopausal patients and $74.8 \%$ in postmenopausal groups [22]. The score offers a predictability based on the value of the two markers but also regarding the menopausal status. Even if the markers are taken individually without the ROMA score, they can still offer a good prediction, for example an endometrioma can be suspected in a female with increased CA125 levels and normal HE4 and malignancy can be strongly suggested by elevated values of both markers.

\section{$R M I$}

Risk of malignancy index (RMI) is a score that combines CA125 values with imagistic findings (ultrasound) and menopausal status. An RMI higher than 200 is correlated with malignancy. The specificity of this score is estimated to be $96.9 \%$ and the sensitivity $85.4 \%$ [13]. From the first proposal of RMI algorithm, there were other formulas proposed with 
modified parameters and cutoff value, but the sensitivity remained similar.

\section{OVAI}

OVA1 is an algorithm that is used to distinguish the pelvic tumor type. The serological markers included are CA125 (increased), apolipoprotein A1 (decreased), $\quad \beta-2$ microglobulin (increased), transferrin (decreased) and pre-albumin (decreased). In addition, the results are correlated with imagining and menopausal status [22]. This test has a sensitivity up to $96 \%$ and specificity up to $40 \%$ [22].

\section{CEA}

Carcinoembryonic antigen (CEA) is a glycoprotein that is a common marker used in different malignancies (ovarian, breast, gastric, pancreatic and lung. It is involved in cell adhesion and, as the name states, in intrauterine development. It is presented in higher levels in utero but after birth the serous levels of healthy adults is decreased [26]. CEA was usual tested with immunoassay methods, but recently aptamer-based biosensors are presented as a better alternative [26]. It is considered that CEA can distinguish between the benign and malignant tumors and also between ovarian neoplasms and ovarian metastases. For epithelial ovarian tumors the CEA dosages have low sensitivity and specificity, but the combination with CA125 and CA199 can improve significantly the diagnostic value [27]. Moro et al [28] included in his study 350 patients with ovarian tumors (99 benign, 43 borderline, 197 ovarian carcinomas) and evaluated the CA125/CEA ratio and CEA alone. The results shown that in the case of multilocular tumors, the markers are not able to distinguish between ovarian metastases and neoplasms. Combined with CA15-3 and CA125, CEA can be used in establishing the etiology of peritoneal effusion [29]. Although there are some controversies regarding the usefulness of CEA, it is considered that CA-125/CEA ratio in addition to RMI can be used for undiagnosed pelvic tumors [30].

\section{Inhibin $A$ and $B$}

Inhibin is found in the serum as dimers with $\alpha$ and $\beta$ subunits. The ovary (granulosa cells) produces this polypeptide and its concentration is

different in pre- and post-menopausal women and also in patients with ovarian tumors (especially granulosa cell tumors and mucinous cancer) $[31,32]$. The main role of inhibin is to inhibit the FSH (follicle-stimulating hormone) secretion. The inhibin hormone is part of the TGF- $\beta$ family (transforming growth factor). In is important to know that mature follicles and corpora lutea form inhibin $\mathrm{A}$ and developing antral follicles form inhibin B [33]. Elevated inhibin values in the post-menopausal women are correlated with granulosa cell tumors and mucinous carcinomas of the ovary, but in epithelial ovarian cancers the values are very low [33] or modestly elevated [31]. Singh et al [34] founded in their study increased inhibin $\alpha$ level in $46 \%$ of endometrial, $51 \%$ of serous and $44 \%$ of mucinous ovarian cancer subtypes and low levels in normal tissue. Also increased inhibin A was correlated with highly differentiated ovarian carcinoma compared to poorly differentiated types (role in cell proliferation) and increased inhibin B levels were correlated in some studies with higher 5 years death rate [35].

An important aspect is represented by the inhibin effect on the angiogenesis and metastasis of the ovarian tumor. Inhibin correlates with tumor angiogenesis which is an important factor that determines the metastasized tumors [34]. High levels of inhibin are correlated with high differentiated cancers [34]. The capacity to predict the poor survival rate is still discussed $[34,35]$.

\section{Lactate dehydrogenase ( $\mathrm{LDH}$ )}

Lactate dehydrogenase is an enzyme that contributes at the growth and survival of the tumor and is increased in different types of cancers [36]. Its implications in tumor metabolism are responsible for the correlation between high LDH levels and poor prognosis. Multiple studies found that increased values were found in patient with ovarian cancers compared to patients with benign tumors or no pelvic tumors at all $[37,38]$. High serum LDH levels in ovarian cancers are correlated with the tumor stage. Survival rates appear to be lower in patients with high LDH expression. [38]

\section{Conclusion}


Multiple biomarkers can be used to evaluate ovarian tumors. By far the most used one is CA125. It is important that the serum results are correlated with menopausal status and available imaging technique. The main purpose of these tests is to identify as early as possible a malignant tumor and to offer a guiding prognosis. The next important step is represented by the treatment protocol. Because ovarian cancer is one of the most aggressive forms of cancer worldwide, a good outcome can be obtained with accurate diagnosis and prompt treatment.

\section{References}

[1] Momenimovahed Z, Tiznobaik A, Taheri S, Salehiniya H. Ovarian cancer in the world: epidemiology and risk factors. Int J Womens Health. 2019;11:287-299. Published 2019 Apr 30. doi:10.2147/IJWH.S197604

[2] Coburn SB, Bray F, Sherman ME, Trabert B. International patterns and trends in ovarian cancer incidence, overall and by histologic subtype. Int $\mathrm{J}$ Cancer. 2017 Jun 1; 140(11):2451-2460.

[3] Yoneda A, Lendorf ME, Couchman JR, Multhaupt HA Breast and ovarian cancers: a survey and possible roles for the cell surface heparan sulfate proteoglycans. J Histochem Cytochem. 2012 Jan; 60(1):9-21.

[4] Sopik V, Iqbal J, Rosen B, Narod SA Why have ovarian cancer mortality rates declined? Part I. Incidence. Gynecol Oncol. 2015 Sep; 138(3):741-9.

[5] Isherwood A, Bamford J, Dupuy AV. Ovarian cancer in select EU countries: incidence, treatable populations and sales by key drug class. Rev Epidemiol Sante Publique. 2018;66:S286. doi:10.1016/j.respe.2018.05.131

[6] Bray F, Ferlay J, Soerjomataram I, Siegel RL, Torre LA, Jemal A. Global cancer statistics 2018: GLOBOCAN estimates of incidence and mortality worldwide for 36 cancers in 185 countries. CA Cancer J Clin. 2018 Nov; 68(6):394-424.

[7] Andrews L, Mutch DG. Hereditary Ovarian Cancer and Risk Reduction. Best Pract Res Clin Obstet Gynaecol. 2017 May; 41():31-48.

[8] Ørskov M, Iachina M, Guldberg R, Mogensen O, Mertz Nørgård B. Predictors of mortality within 1 year after primary ovarian cancer surgery: a nationwide cohort study. BMJ Open. 2016 Apr 21; 6(4):e010123.

[9] Prat, Jaime, and FIGO Committee on Gynecologic Oncology. "FIGO's staging classification for cancer of the ovary, fallopian tube, and peritoneum: abridged republication." Journal of gynecologic oncology vol. 26,2 (2015): 87-9. doi:10.3802/jgo.2015.26.2.87.
[10] Karen Eagle Jonathan A. Ledermann Tumor Markers in Ovarian Malignancies. The Oncologist. 01 October 1997 https://doi.org/10.1634/theoncologist.2-5-324.

[11] Malati Tangirala, G. Rajani Kumari, B Yadagiri. Application of tumor markers in ovarian malignancies. Indian Journal of Clinical Biochemistry 16(2):224-33 - July 2001.

[12] Meinhold-Heerlein I, Fotopoulou C, Harter P, Kurzeder C, Mustea A, Wimberger P, Hauptmann S, Sehouli J. The new WHO classification of ovarian, fallopian tube, and primary peritoneal cancer and its clinical implications. Arch Gynecol Obstet. 2016 Apr;293(4):695-700. doi: 10.1007/s00404-016-40358. Epub 2016 Feb 19.

[13] Dochez V, Caillon H, Vaucel E, Dimet J, Winer $\mathrm{N}$, Ducarme G. Biomarkers and algorithms for diagnosis of ovarian cancer: CA125, HE4, RMI and ROMA, a review. J Ovarian Res. 2019;12(1):28. Published 2019 Mar 27. doi:10.1186/s13048-0190503-7.

[14] Bast RC Jr, Feeney M, Lazarus H, Nadler LM, Colvin RB, Knapp RC. Reactivity of a monoclonal antibody with human ovarian carcinoma. J Clin Invest. 1981 Nov; 68(5):1331-7.

[15] Enakpene CA, Omigbodun AO, Goecke TW, Odukogbe AT, Beckmann MW. Preoperative evaluation and triage of women with suspicious adnexal masses using risk of malignancy index. J Obstet Gynaecol Res. 2009 Feb; 35(1):131-8.

[16] Clarke-Pearson, D. L. (2009). Clinical practice. Screening for ovarian cancer. N. Engl. J. Med. 361, 170-177. doi: 10.1056/NEJMcp0901926.

[17] Wei-Lei Yang, Zhen Lu, and Robert C. Bast Jr. The Role of Biomarkers in the Management of Epithelial Ovarian Cancer. Expert Rev Mol Diagn. 2017 June ; 17(6): 577-591. doi:10.1080/14737159.2017.1326820.

[18] Rustin GJ, van der Burg ME, Griffin CL, et al. Early versus delayed treatment of relapsed ovarian cancer (MRC OV05/EORTC 55955): a randomised trial. Lancet. 2010; 376(9747):1155-1163.

[19] van Nagell JR Jr, DePriest PD, Ueland FR, et al. Ovarian cancer screening with annual transvaginal sonography: findings of 25,000 women screened. Cancer. 2007; 109(9):1887-1896.

[20] Welsh JB, Zarrinkar PP, Sapinoso LM, et al. Analysis of gene expression profiles in normal and neoplastic ovarian tissue samples identifies candidate molecular markers of epithelial ovarian cancer. Proc Natl Acad Sci U S A. 2001; 98(3):1176-1181.

[21] Kirchhoff C, Habben I, Ivell R, Krull N. A major human epididymis-specific cDNA encodes a protein with sequence homology to extracellular proteinase inhibitors. Biol Reprod. 1991 Aug; 45(2):350-7.

[22] Simmons, Archana R et al. "The emerging role of HE4 in the evaluation of epithelial ovarian and 
endometrial carcinomas." Oncology (Williston Park, N.Y.) vol. 27,6 (2013): 548-56.

[23] Lu R, Sun X, Xiao R, Zhou L, Gao X, Guo L. Human epididymis protein 4 (HE4) plays a key role in ovarian cancer cell adhesion and motility. Biochem Biophys Res Commun. 2012 Mar 9; 419(2):274-80.

[24] Iwahori K, Suzuki H, Kishi Y, Fujii Y, Uehara R, Okamoto N, Kobayashi M, Hirashima T, Kawase I, Naka T. Serum HE4 as a diagnostic and prognostic marker for lung cancer. Tumour Biol. 2012 Aug; 33(4):1141-9.

[25] Nagy B Jr, Krasznai ZT, Balla H, Csobán M, Antal-Szalmás P, Hernádi Z, Kappelmayer J. Elevated human epididymis protein 4 concentrations in chronic kidney disease. Ann Clin Biochem. 2012 Jul; 49(Pt 4):377-80.

[26] Xiang W, Lv Q, Shi H, Xie B, Gao L. Aptamerbased biosensor for detecting carcinoembryonic antigen. Talanta. 2020 Jul 1;214:120716. doi: 10.1016/j.talanta.2020.120716. Epub 2020 Jan 11. [27] Guo, J., Yu, J., Song, X., \& Mi, H. (2017). Serum CA125, CA199 and CEA Combined Detection for Epithelial Ovarian Cancer Diagnosis: A Metaanalysis. Open medicine (Warsaw, Poland), 12, 131137. https://doi.org/10.1515/med-2017-0020.

[28] Moro F, Pasciuto T, Djokovic D, Di Legge A, Granato V, Moruzzi MC, Mancari R, Zannoni GF, Fischerova D, Franchi D, Scambia G, Testa AC. Role of CA125/CEA ratio and ultrasound parameters in identifying metastases to the ovaries in patients with multilocular and multilocular-solid ovarian masses. Ultrasound Obstet Gynecol. 2019 Jan;53(1):116-123. doi: 10.1002/uog.19174.

[29] Kiluk MS1, Rółkowski R, Zawadzki RJ, Wojtukiewicz MZ. Usefulness of CEA, CA 15-3 and CA 125 tumor markers in the differential diagnostics of peritoneal effusion. Pol Merkur Lekarski. 2002 Oct;13(76):298-301.

[30] Sofie Sølvsten Sørensen \& Berit Jul Mosgaard. Combination of cancer antigen 125 and carcinoembryonic antigen can improve ovarian cancer diagnosis. Dan Med Bul 58/11 November 2011.
[31] I Cooke, M O'Brien, FM Charnock, N Groome and $\mathrm{T} S \mathrm{~S}$ Ganesan. Inhibin as a marker for ovarian cancer. BUsh Jojam d Cmc (1 ) 71, 1046-1050f (C) 1995 tocddon Press Al rhts reseved 0007-0920/95.

[32] Healy DL, Burger HG, Mamers P et al.: Elevated serum inhibin concentrations in postmenopausal women with ovarian tumours. N. Engl. J. Med. 329, 1539-1542 (1993).

[33] David M Robertson \& Martin K Oehler. Emerging role of inhibin as a biomarker for ovarian cancer. Future Medicine Ltd ISSN 1745-5057 Women's Health (2005) 1(1), 51-57. 10.1517/17455057.1.1.051.

[34] Singh, P., Jenkins, L. M., Horst, B., Alers, V., Pradhan, S., Kaur, P., Srivastava, T., Hempel, N., Győrffy, B., Broude, E. V., Lee, N. Y., \& Mythreye, K. (2018). Inhibin Is a Novel Paracrine Factor for Tumor Angiogenesis and Metastasis. Cancer research, 78(11), 2978-2989. https://doi.org/10.1158/0008-5472.CAN-17-2316.

[35] Walentowicz, P., Krintus, M., Sadlecki, P., Grabiec, M., Mankowska-Cyl, A., Sokup, A., \& Walentowicz-Sadlecka, M. (2014). Serum inhibin A and inhibin B levels in epithelial ovarian cancer patients. PloS one, 9(3), e90575. https://doi.org/10.1371/journal.pone.0090575.

[36] Jiangdong Xiang Lina Zhou Yan Zhuang Jin Zhang Ya Sun Shuangdi Li Zhenbo Zhang Gao Zhang Yinyan He. Lactate dehydrogenase is correlated with clinical stage and grade and is downregulated by si-SATB1 in ovarian cancer. ONCOLOGY REPORTS 42788 0: 2788-2797, 2018. DOI: $10.3892 /$ or.2018.6658.

[37] Schneider D, Halperin R, Langer R, Bukovsky I, Herman A. Peritoneal fluid lactate dehydrogenase in ovarian cancer. Gynecol Oncol. 1997 Sep;66(3):399404.

[38] Xiang J, Zhou L, Zhuang Y, Zhang J, Sun Y, Li S, Zhang Z, Zhang G, He Y. Lactate dehydrogenase is correlated with clinical stage and grade and is downregulated by si-SATB1 in ovarian cancer. Oncol Rep. $2018 \quad$ Nov;40(5):2788-2797. doi: 10.3892/or.2018.6658. Epub 2018 Aug 17. 